\title{
DVR Pilot Study: Measuring Uses and Gratifications of Digital Video Recorders in Modern Television Viewing
}

\section{Elizabeth A Thomas*}

Mass Communications, Murray State University, USA

\begin{abstract}
The use of digital video recorders (DVRs) has caused concern among advertisers and the television industry. Many have argued that the 30 -second ad is no longer effective because users of digital video recorders are fastforwarding though commercials. This denies the potential actual usage of the DVR in modern television viewing. Bio-metric research has suggested that it is not the behavior of fast-forwarding that matters most, but actual viewing patterns and choices viewers make coupled with memories of previously-viewed advertisements. In the process of fast-forwarding, viewers must pay attention to passing images and are capable of not only recognizing advertisements but altering their viewing to incorporate DVR use. DVRs are used in order to view specific advertising content based on multiple factors, including past emotional memories. Visual cues within advertising are often provocative enough to stimulate action - stopping viewers from fast-forwarding through ads. Still, the idea persists that when viewers do fast-forward through television advertisements, the ads have a reduced effectiveness. This broad assumption ignores the fact that DVR owners report watching more television, using their DVRs for the primary benefit of time shifting - and not fast-forwarding through advertising. The central motivation for using DVR technology is the ability to watch programming at convenient times. In attempting to avoid advertising, most viewers do, in fact, pay attention to their TV screens. Doing so may result in viewers inadvertently paying even more attention to advertising messages.
\end{abstract}

\section{Introduction}

In recent years, television has become the favorite scapegoat of media critics, many of whom predict that loss of television ad revenues and the belief that digital video recorders are "causing" viewers to skip ad messages will lead to the general decline of a major media industry. By allowing viewers to skip advertising, the increasing popularity of DVRs carries implications for both advertisers and television. Further study is required to investigate exactly how consumers are using DVRs in the current environment.

A 2003 study in Cable World magazine predicted that the number of U.S. households with DVRs would grow to over 60 million by the end of 2011 [1]. The actual number of households using DVRs in 2009 is 43.7 million [2]. Does this necessarily mean that advertisers are having a harder time reaching people who can fast-forward through commercials? The researcher hoped to gain insight into the uses and gratifications of DVR technology among modern television viewers.

\section{Literature Review}

The digital video recorder first hit the market in 1997 when TiVo, Inc. opened its doors for business [3]. A digital video recorder (DVR) or TiVo is a device that records video in a digital format to a disk drive or other memory medium within a device. The term includes standalone set-top boxes, portable media players and software for personal computers which enables video capture and playback to and from disks.

Since TiVo was introduced, the company name has become synonymous with DVR devices. For purposes of the study, TiVo and other digital video recording devices are often referred to as DVRs. Researchers and advertisers have written a plethora of articles about the TV/DVR revolution, a phenomenon that may or may not actually make broadcast advertising less desirable. Forecasts for consumer adoption of DVR technology have been corrected downward in recent years as market penetration lagged projections [4]. Early researchers considered the DVR a hardware innovation which would lead to superior control over TV content. In contrast, authors later called the DVR a supplyside service innovation which simply allowed distributors to offer content in more convenient ways, therefore expanding their share of market [4]. In order to address the effects of DVR usage on viewing, it is necessary to consider the genesis of "time shifting." The phenomenon began in 1980 as early adopters of the video cassette recorder (VCR) saw the device as a technological key in a new age of selective mass media use or narrowcasting [5]. VCR use changed the old pattern of relatively indiscriminant television viewing into one of more "active" behavior, involving a high degree of viewer involvement and choice, often referred to as "zipping" and "zapping" with the use of a remote control. The television industry has anticipated each new technological advance with more than a little trepidation. From the first remote control device to VCRs and now DVRs, similarities exist between each of the technological conveniences which consistently give consumers greater control over TV content and viewing. Initial studies indicated that VCR ownership affected leisure-time budgets and overall media consumption in a positive manner [5]. The same may be said of the DVR.

Early studies of VCR users indicated that viewers used the device as a complement to and not a replacement for regular TV viewing patterns. Time-shifting represented the overwhelming use of home

*Corresponding author: Elizabeth A Thomas, Mass Communications, Murray State University, USA, Tel: (270) 809-5441; E-mail: elizabeth.thomas@murraystate.edu

Received January 06, 2012; Accepted January 28, 2012; Published January 30 2012

Citation: Thomas EA (2012) DVR Pilot Study: Measuring Uses and Gratifications of Digital Video Recorders in Modern Television Viewing. J Mass Communicat Journalism 2:109. doi:10.4172/2165-7912.1000109

Copyright: (c) 2012 Thomas EA. This is an open-access article distributed unde the terms of the Creative Commons Attribution License, which permits unrestricted use, distribution, and reproduction in any medium, provided the original author and source are credited. 
video recorders throughout the 1980s [6]. Instead of simply choosing alternate program content when they could not be home to watch, a VCR household could rearrange the broadcast schedule, making viewing more convenient or eliminating conflicts entirely. More than three-quarters of all programs recorded on VCRs were "rebroadcast" at a different hour than originally scheduled, demonstrating the degree to which technology allowed individuals to manipulate broadcast schedules to meet their own time constraints. Researchers at the time reported fragmentary findings but suggested that VCR households used recorders most often to "time-shift" viewing, in other words, to replay broadcasts at a later time [5].

Time-shifting also appeared to increase the total size of the broadcast audience, since programs which would otherwise be missed were captured on tape for subsequent, often multiple, replays. Nearly half of VCR households reported watching more television as a result of owning a VCR. The same is true in the current switch to digital video recorders in the new millennium [7].

The introduction of the DVR in 1997 took "time-shifting" to new heights. In 2003, penetration of the DVR market in the United States was just 3\% [1]. In the fall of 2004, a two-part investigation broke new ground by exploring the mind of the DVR user. The initial report focused on adoption of DVR technology and characterized "high levels of enthusiasm and infectious word-of-mouth" as the central user characteristics, according to the Forrester Research Group [1]. A second article by the group delved deeper into the effects of DVR use, drawing clear attention to the impact of technology on television advertising. The Forrester study in 2004 is significant as one of the first in-depth surveys on the viewing habits of DVR users.

In 2004, DVR users were reportedly spending nearly $60 \%$ of their total TV time watching recorded programs and skipping up to $92 \%$ of commercials [1]. Further study indicated the average DVR user viewed $46 \%$ of advertising across all programs watched, similar to results from early VCR ad-skipping studies [8]. DVR adoption was expected to continue to increase rapidly, putting new pressure on networks and advertisers. Research, however, indicated a high degree of unevenness in ad skipping as consumers gained familiarity with the new technology. TiVo users and young women were reportedly the most likely to skip TV commercials [1].

Total DVR viewers in the Forrester Research study (2004) demonstrated a tendency to stop ad-skipping in order to watch humorous ads, movie trailers, and ads in news or sports programming. The Forrester Research additionally recommended that advertisers focus on increasing creativity within ad messages, placing ads within movie trailers, and network promos, and developing new ad elements which could persist through fast-forwarding. In a more recent report (2009), 52.3 million U.S. households or $44 \%$ of all homes are expected to have a DVR or similar device by 2014 , a figure which rose from $3 \%$ to $44 \%$ market penetration over the course of a decade [9]. TVWeek. com reported that from 2004 to 2014, "DVR technology is expected to erode total viewer impressions but be offset by an overall increase in television viewing" [10].

Another report in 2009 suggested that upscale households account for a disproportionate slice of the DVR pie with more than half of all U.S. homes with incomes of at least $\$ 100,000$ subscribing to some form of time-shifting device. With $29 \%$ of U.S. television homes equipped with DVRs, there is currently a commercial-skipping device of some kind in approximately 43.7 million households [9].
In 2009, the Mendelsohn Affluent Survey reported that $63 \%$ of people earning $\$ 100,000$-plus enjoy DVR capability today. This translates to at least one DVR in approximately 15 million affluent households - a market segment of particular interest to advertisers [11].

Despite increased focus on the impact of DVR usage and ownership, there remains a distinct lack of evidence regarding viewers' direct experiences in time-shifting TV advertising. In 2008, yet another landmark study employed bio-metrics and scientific eyetracking to add insight into the efficacy of information processing during fast-forwarded television content [12]. Results indicated that when compared with a control group viewing ads in real-time, viewers watching the same content in fast-forward recalled the same ads at significantly higher rates than expected, given the speed at which content had been viewed [12].

Researchers have demonstrated that the speed at which neurons classify observations based on previous exposures is important in this equation [7]. Eye-tracking data indicated that viewers in the DVR group spent significantly more time looking at the center of the TV screen, more time with their eyes focused on the screen, and produced a substantially higher amount of visual processing activity as images flashed by at top speed. These results indicate that DVR users are not only watching time-shifted advertising, but they are doing so with heightened attention which may actually boost ad effectiveness [13].

Exploration into the DVR market of 2006 saw researchers paying particular attention to TiVo, the earlybrandleader. Initially, broadcasters and advertisers reacted to the DVR surge with trepidation. Later, many came to realize the potential to use TiVo technology for data collection as well as target marketing. Some saw this as an opportunity to help shape changes in the TV industry. TiVo characterized its corporate relationship with broadcasters and advertisers as advantageous rather than contentious. TiVo users enjoyed greater control through timeshifting and increased functionality through content playback, while presenting existing television producers with a new platform for audience surveillance [14].

An alternate perspective regards the DVR as a simple service innovation that has altered the distribution of TV content. By this reasoning, the DVR is a device offered by distributors to allow the audience to locate desired content within an offering. It is an enhanced set-top box where recording and time-shifting functionality is complemented by superior navigation, consumer tracking, and the possibility to "narrowcast" individualized content [14].

In a study conducted this year [15], researchers reported that while $84 \%$ of DVR owners rated the ability to skip commercials as very important, only $8 \%$ indicated it was the greatest benefit of owning the recording device. In other words, it is still not known that viewers will necessarily fast-forward through ads just because they can. Adskipping has not been a primary motivation for DVR use.

This study attempted to shed additional light on modern television viewing habits as consumers have become more familiar with the DVR The questions posed in the next section incorporate demographic variables and consider whether they have any bearing on whom, how, and whether or not people use ad-skipping technology to its fullest potential. In cases where advertising was being skipped via DVR use, the study sought additional clues regarding the motivations behind such behavior, and trends in how DVR technology was being employed. 


\section{Research Questions}

Little research to date has explored exactly how the changing media landscape affects consumers' perceptual processes. By altering the way visual stimuli are presented, fast-forwarding should also alter viewers' patterns of perception. The study sought to glean insight about changes in viewing habits brought on by the widespread adoption of DVR technology, and considered demographic factors such as gender, age, and education level. The study addressed the following research questions:

\section{R1: Do men and women use DVRs similarly or differently?}

R2: Does age, gender, or level of education have bearing on whether or not an individual uses a DVR or not? How does DVR use relate to overall television consumption?

R3: Do demographic influences like age, gender, or education play a role in whether or not advertising is skipped (via DVR fastforwarding) or the frequency of ad skipping?

R4: What portion of the DVR-using audience is more likely to stop fast-forwarding in order to view advertisements, and if so, with what frequency?

R5: Do different types of advertising (ad content) induce viewers to respond to visual cues? Are certain of these cues more "provocative" than others? Are they strong enough to motivate decreased adskipping?

\section{Methodology}

The research instrument consisted of 18-questions in an online survey disseminated via email to a random sampling of the population of a medium-sized university in the southeastern U.S. Survey invitations were emailed to staff and faculty members of the College of Business, the College of Humanities and Fine Arts, and the College of Science, Engineering and Technology at Murray State University. The time frame for conducting the research was September 30 to October 16, 2009.

A total of 1,025 invitations were sent to address lists supplied by each college ( 350 invitations) and to every $12^{\text {th }}$ student listed in a 2008-2009 campus telephone directory (675 invitations). Another 30 invitations were sent to random faculty members who were asked to share the survey link with their students. A total of 236 respondents completed the entire survey; 244 individuals responded to at least some portion of the survey. Of those responding, 109 indicated that they were active DVR users. The overall response rate was approximately $23.8 \%$ ( $1025 \times 244$ respondents). A more accurate response rate of $29.5 \%$ was calculated when the researcher corrected for non-delivery of 200 invitations. Diversity within the survey distribution was achieved through the inclusion of faculty members, staff members, and students, selected randomly and representing varying age groups $(18-65+)$, a broad range of incomes, and various levels of education. The three distinct groups allowed for a microcosmic view of the usage habits of an entire university population.

The email invitation to the survey contained an informed consent document and a link directing respondents to the research instrument located online at SurveyMonkey.com. Responses automatically populated within a professional user's account at SurveyMonkey.com. Results were collected and analyzed between October 23 and October 30,2009 , employing cross-tabulation as a primary tool for analysis.
The survey contained 18 multiple-choice and open-ended questions. The research vehicle was approved by the Murray State University Institutional Review Board.

\section{The Respondents}

Of 236 respondents who completed the survey, $32.6 \%(\mathrm{~N}=77)$ were female students and $10.6(\mathrm{~N}=25)$ were male students, identifying a total of $43.2 \%(\mathrm{~N}=103)$ of total respondents as students. University staff members comprised $14.4 \%(\mathrm{~N}=34)$ of total respondents. Female faculty members represented $14.8 \%(\mathrm{~N}=35)$ of the responding population. Male faculty members comprised $28.4 \%(\mathrm{~N}=67)$ of respondents. A greater number of female students and male faculty members participated in the pilot study, although total distribution of responses with regard to age, gender, and employment status, closely resembled the university's overall population.

Of the 244 respondents who began the survey, $44.7 \%(\mathrm{~N}=109)$ were DVR users. Among these, $45.7 \%(\mathrm{~N}=47)$ were students; $11.6 \%(\mathrm{~N}=12)$ were staff members, and $42.7 \%(\mathrm{~N}=44)$ were faculty members. Of the DVR users, $55.3 \%(\mathrm{~N}=57)$ were female, and $44.7 \%(\mathrm{~N}=46)$ were male

Fifteen multiple-choice survey questions (see Appendix) corresponded to research questions, while three questions were designed to filter demographic data, and aid in cross tabulation of results. The focus of the study was current users of DVR technology, frequency of DVR usage, types of programming viewed live versus recorded, and advertisements that motivated viewers to stop timeshifting advertising content.

A critical question was: "Do you ever use a DVR (or TiVo) to record TV programs?" Of 244 respondents, $44.7 \%(\mathrm{~N}=109)$ answered in the affirmative, while $58.2 \%(\mathrm{~N}=135)$ said they did not use DVR technology at the time. Those answering "no" were automatically moved ahead to demographic questions using skip logic built into the research instrument. The remaining 16 questions were answered only by respondents who stated that they regularly used a DVR or similar device.

Of the 109 DVR-users, $37.9 \%(\mathrm{~N}=39)$ were students, while the remaining $62.1 \%(\mathrm{~N}=64)$, was comprised of faculty and staff members, implying that greater than $60 \%$ of respondents had completed a fouryear degree program, or attained a higher degree (master's, doctoral or other).

\section{Results}

RQ1: Do men and women use DVRs similarly or differently? Of the three distinct groups - students, university staff, and faculty members more female students and staff members indicated regular use of DVRs than their male counterparts. More male faculty members responded that they used the device than did female faculty members. The number of male faculty members using DVR technology surpassed the usage by female students who were expected, based on prior research, to exhibit the highest level of use (see literature review). While $10.2 \%$ $(\mathrm{N}=24)$ of all respondents were female staff members, $37.5 \%(\mathrm{~N}=9)$ of this population indicated they used a DVR versus $62.5 \%(\mathrm{~N}=15)$ who did not. Of the total respondents, $32.6 \%(\mathrm{~N}=77)$ were female students, 45.4\% ( $\mathrm{N}=35)$ were DVR users, and $54.5 \%(\mathrm{~N}=42)$ were not. Female faculty members comprised $14.8 \%(\mathrm{~N}=35)$ of respondents; of these, 37.1\% $(\mathrm{N}=13)$ used DVRs versus $62.8 \%(\mathrm{~N}=22)$ who did not. While DVR usage was significant among the traditionally younger, less affluent female students, it was slightly lower than among the older male population. 
Among male respondents, staff members exhibited lower usage levels than the other two groups. However, staffers comprised only $4.2 \%(\mathrm{~N}=10)$ of total respondents. Within this group, 30\% $(\mathrm{N}=3)$ indicated they used a DVR versus $70 \%(\mathrm{~N}=7)$ who did not.

In the total survey population, $10.6 \%(\mathrm{~N}=25)$ were male students. Among these, $48 \%(\mathrm{~N}=12)$ used a DVR versus $52 \%(\mathrm{~N}=13)$ who did not. DVR usage among the female student population was similar to that of the traditionally older, more educated, more affluent male faculty members. Male faculty members using DVRs totaled $28.4 \%$ $(\mathrm{N}=67)$ of total respondents. Within the group, $46.2 \%(\mathrm{~N}=31)$ used DVRs versus $53.7 \%(\mathrm{~N}=36)$ who did not, rivaling the finding among the female students.

Based on data illustrated in Figure 1, results were evenly divided regarding the impact of gender on DVR use. Female students (representing TV advertisers' most desirable market segment) were just as likely to be active DVR users as a similar-sized audience of older, more affluent males.

RQ2: Does age, gender, or level of education have bearing on whether or not an individual uses a DVR or not? How does DVR use relate to overall television consumption?

Age distribution among survey respondents is broken down in Figure 2, and demonstrates a broad range of market segments represented within the traditional campus population. This data contrasts with the previously held notion that DVR (and general television) use is highest among females age 18-24 [16]. As initially discussed in RQ1, the largest two groups of DVR users by gender were female students and male faculty members, with no easily recognizable correlation. Education presented yet another variable. Figure 2 illustrates the age groups based on whether or not they used DVR technology.

Among responding DVR users, 62.1\% (64) graduated from a 4-year college program or attained a higher degree (Master's, Ph.D., or other). It is reasonable to assume that this segment was comprised of faculty and staff members, since all remaining respondents were currently students. Still, the study did not include any non-student respondents, making it less clear whether higher education played a role in the choice to utilize DVR technology.

\section{Television Consumption and Age}

Audiences watching live broadcasts tend to skew older, according to a 2008 report in Media Life Magazine. This report indicated that when it comes to live viewing, the median viewer age has now climbed to 50. That's one year older than the top end of the demographic most targeted by advertisers, adults 18-49 [16]. The median age of the general broadcast audience has been trending up for the past decade. DVR usage may be a significant factor influencing this rise. Early research indicated more prevalent use of DVRs among younger viewers. The current study does not support this result. If fewer young people are watching shows as they air, then the median age of the networks' liveonly audiences is rising [16].

The problem for advertisers lies in not knowing whether ads are being seen or not by viewers who may zip and zap through recorded programming. According to Magna Global, the research firm that conducted the Media Life study on age related to TV usage, "The median age of CBS's audience is 54 years old. For ABC, its 50 and for NBC, it's 49 years old. The median age of Fox's audience is 44 and the CW's is 34" [16]. If, as previously mentioned, nearly one-fourth of homes have a DVR [2], then approximately $9 \%$ of all TV is being viewed on

\section{Male vs. Female - Who uses the DVR most?}

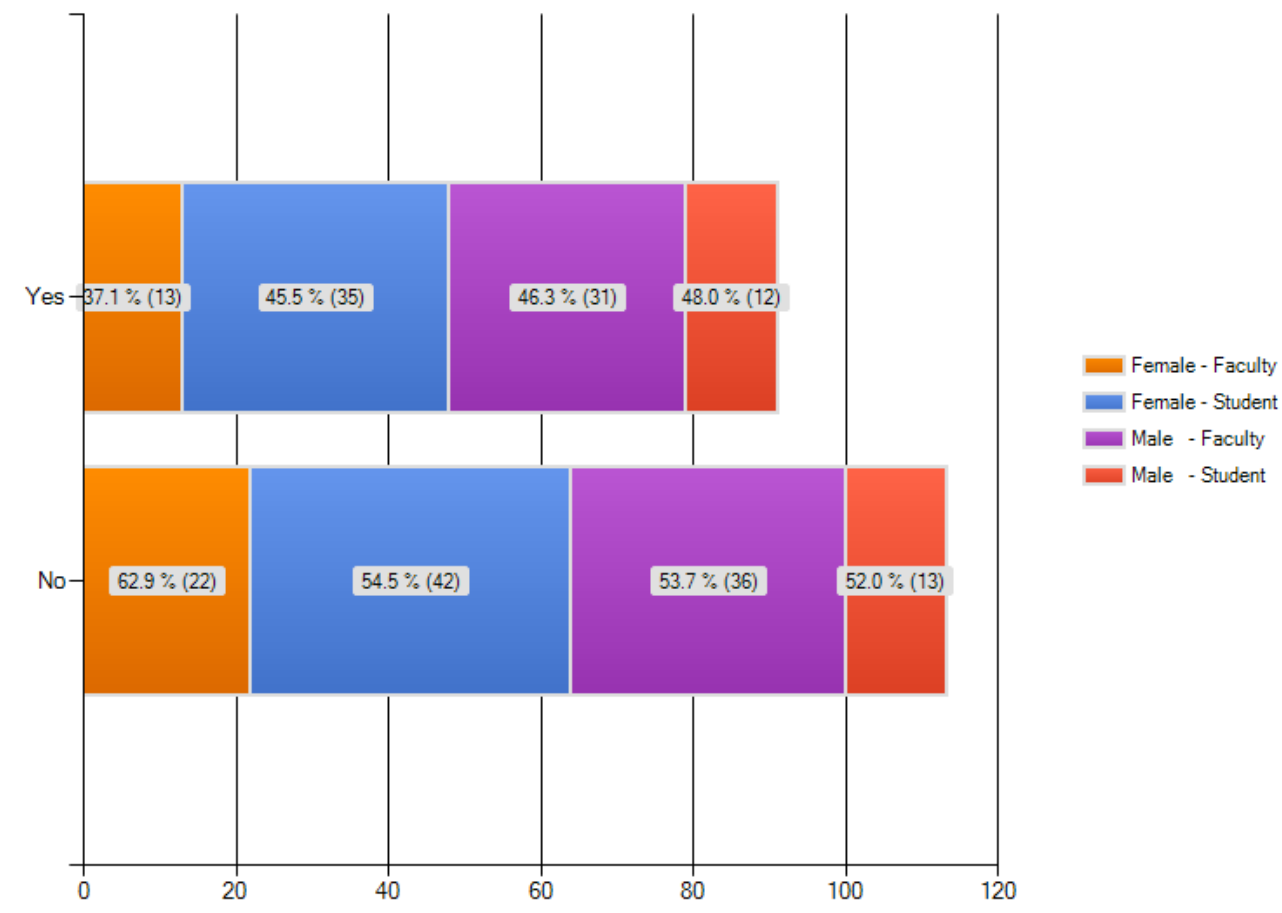

Figure 1: (Yes = Active DVR Users; No = non DVR-users). 
Citation: Thomas EA (2012) DVR Pilot Study: Measuring Uses and Gratifications of Digital Video Recorders in Modern Television Viewing. J Mass Communicat Journalism 2:109. doi:10.4172/2165-7912.1000109

\section{DVR Use by Age Group}

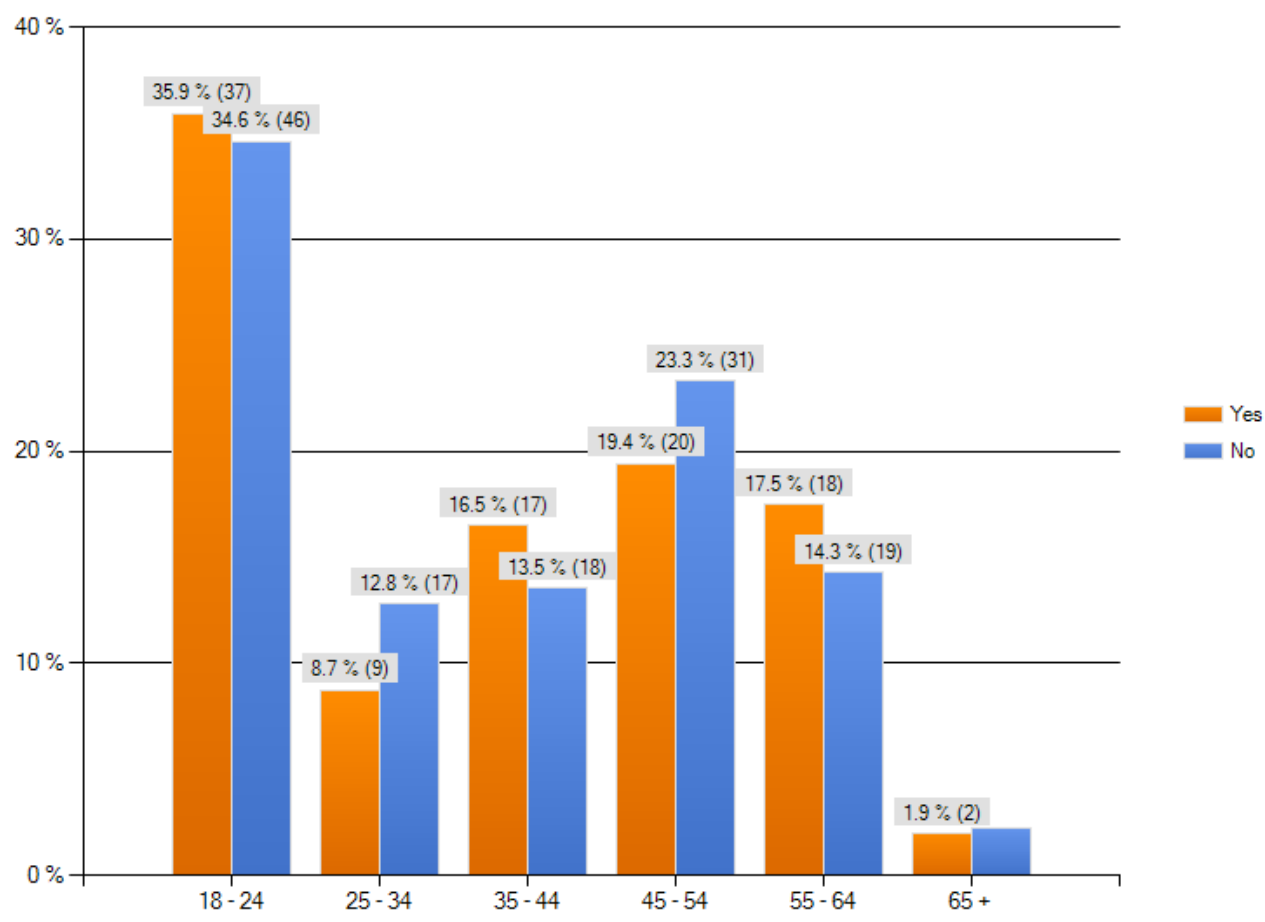

Figure 2: (\% in each column represents the sub-group's \% within the total of respondents)

\section{Frequency of DVR usage}

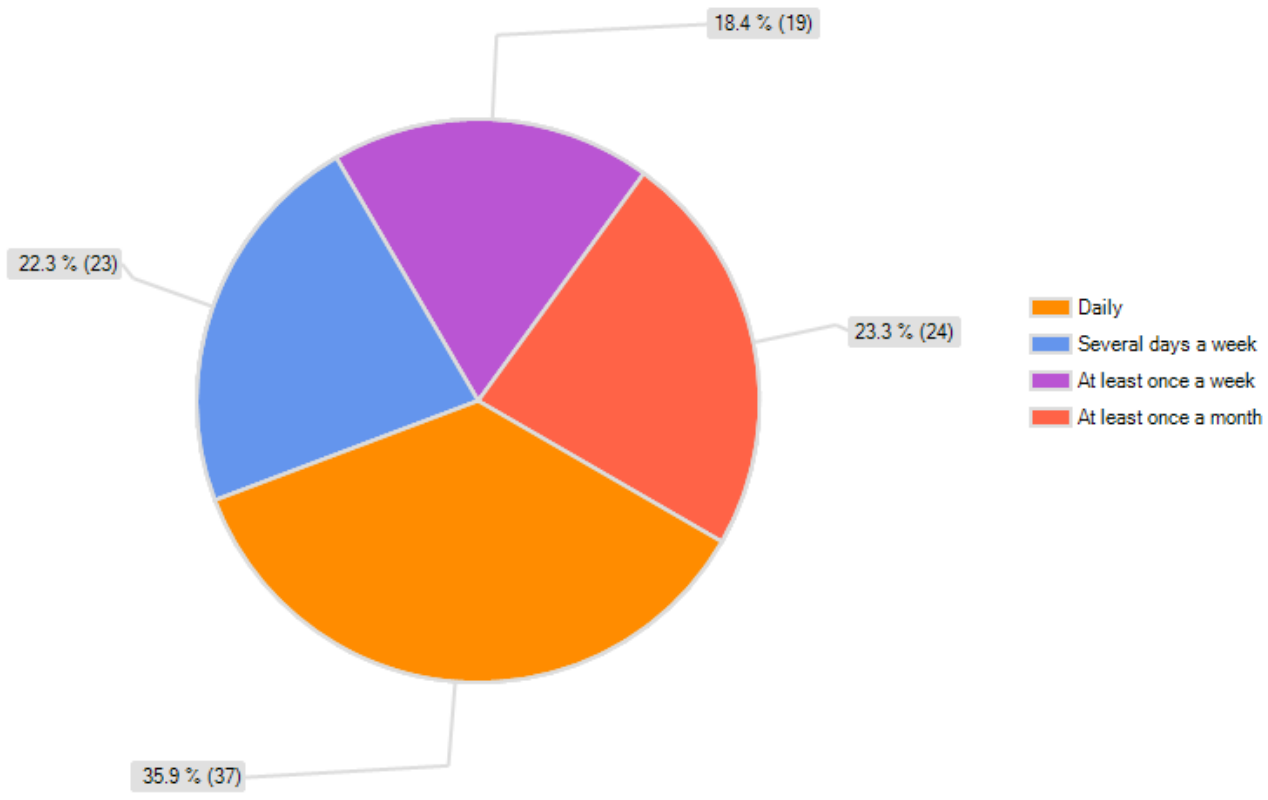

Figure 3:

DVRs after original broadcast. If young people are more inclined to record programming, then shows that target them, like NBC's Heroes, may draw as much as 20 percent of their viewership after the initial programs airs. Reports indicate that DVR viewers could be 10 or more years younger than audience members who watch original broadcasts [16].

Figure 3 illustrates that more than half of the DVR users in the study used the technology with a measured frequency - daily or at least 
several days per week. A total of $35.9 \%(\mathrm{~N}=37)$ of respondents reported using their DVRs daily, while $22.3 \%(\mathrm{~N}=23)$ used the device at least several days per week.

It is still unclear how many viewers watch commercials in playback, although the study supports the concept that people watching programming in playback may actually pay more attention to both the program and the commercials than they do when viewing live programming.

RQ3: Do demographic influences like age, gender, or education play a role in whether or not advertising is skipped (via DVR fast-forwarding) or the frequency of ad skipping. Of the 109 respondents who used DVRs, $70.5 \%(\mathrm{~N}=74)$ said they "always" used the device to fast-forward through commercials. Those who responded that they fast-forwarded through ads only "sometimes" included the remainder, $29.5 \%(\mathrm{~N}=31)$, of all respondents. Question number four in the research instrument offered two answers which were not selected by any of the respondents. None selected that they "rarely" or "never" fast-forwarded through advertising.

The current findings, as shown in Figure 4, demonstrate that all DVR users "sometimes" fast-forward through advertising. The assumption herein is that respondents always viewed some portion of TV advertising. An additional 3.8\% $(\mathrm{N}=4)$ of respondents said they did not know whether they stopped fast-forwarding or not, rendering their answers unusable in this analysis.

It is encouraging that more than half of all DVR users in the study said they used their DVR's fast-forward function to view advertising that "caught their attention." More than three-quarters of DVR users or $76.2 \%(\mathrm{~N}=80)$ said they noticed which products were being promoted within the skipped TV ads because they recognized ad characteristics, logos, and brand names while they were fast-forwarding.
RQ4: What portion of the DVR-using audience is more likely to stop fast-forwarding in order to view advertisements, and if so, with what frequency? A significant portion of the general audience is likely to stop fast-forwarding in order to view an advertisement, as evidenced in Figure 5. More than half, 56.2\% ( $=59)$ of the 105 DVR-using respondents in the study indicated that they "often," "sometimes," or at least "rarely" used their DVRs to stop fast-forwarding with the specific intent of viewing television commercials. This compared to $42.9 \%(\mathrm{~N}=45)$ who said they did not stop fast-forwarding to view advertisements.

RQ5: Do different types of advertising (ad content) induce viewers to respond to visual cues? Are certain cues more provocative than others? Are they strong enough to motivate decreased ad-skipping? Certain types of advertising for specific products or services did, in fact, compel the DVR users to stop using the fast-forward function specifically to watch advertisements. Prior studies support that emotive advertising is more successful at promoting recall, and producing sales effects. Advertising works best when it is emotional [7]. Here, certain visual cues were provocative enough to lead to action. Respondents selectively used their DVRs to view advertisements - rather than to avoid them. A single, open-ended question was critical: "What type of ad, product, or service caused you to pause your DVR fast-forwarding and watch the commercial?" Of the 105 active DVR users surveyed, 54 individuals provided open-ended responses to the question. Comments provided ranged from those who said they stopped fastforwarding to view ads for new cars and children's toys, to one individual who mentioned stopping to see an ad about a new antidepressant on the market. Several gave responses similar to the statement: "I don't recall the exact product, but I know I stop fast-forwarding all the time." Certain responses were repeated several times with varied phrasing. The most popular answer was "I stop (fast-forwarding) to view ads for

When viewing a program you recorded, do you fast-forward through the commercials?

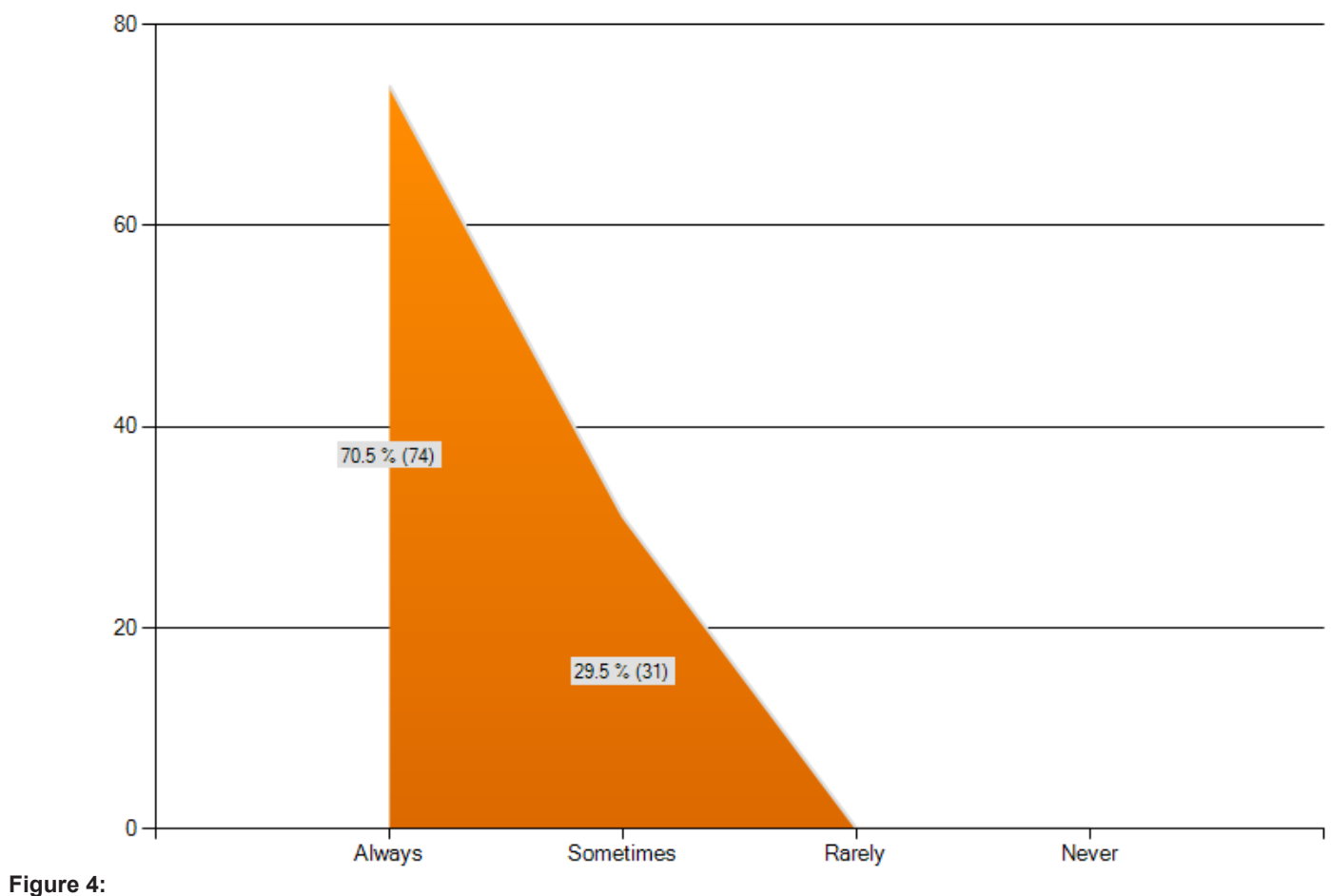


movies or movie trailers" (10 matching responses out of 54). This was closely followed by the mention of ads with previews for TV programs.

Specific creative content from advertising campaigns was cited by respondents. For example, DVR users reported stopping to watch ads they found "humorous or fun," and some mentioned campaigns like the "Mac vs. PC" ads by Macintosh, and the "Happy Cow" campaign by the California Milk Advisory Board. A recurring theme among the overall responses was that something visually unique, appealing, or humorous in an ad was most likely to catch the eye during fast-forwarding.

Following is a list of the top comments collected from open-ended responses. Each was mentioned more than once or echoed by multiple respondents in other answers:

- Any commercial that could possibly be funny

- Movie trailers

- News teasers

- Anything exercise related

- The talking babies

- The "happy" cows

- Anything featuring an app for my iPhone

- That Traveler's insurance ad with the dog

- Anything featuring an actor I like

- The Thermasilk commercials

- Most ads for upcoming TV shows

- Cars and electronics

- Anything for a new product I might be interested in

- Ads for sporting events

- Ads for "as seen on TV products"
The most common single response for stopping the use of the fastforward function on the DVR was to view "commercials that looked like they might be funny."

Clearly, DVR users in the sample recalled TV advertising even as they reported fast-forwarding through ad content "much of the time."

The study revealed that viewing habits may have as great an impact on recognition and recall of television advertising as DVR usage. Figure 6 shows that nearly $25 \%(\mathrm{~N}=26)$ of DVR-using respondents indicated a television is generally turned on (always) in their households, although they may not be actively watching. This suggests that nearly one quarter of the population may be (consciously or subconsciously) exposed to additional advertising messages at the aural level. In other words, they may hear more advertising than they see. Also significant to these findings was that $31.4 \%(\mathrm{~N}=33)$ of respondents said they primarily watched television through the use of a DVR. The number of respondents who rarely watched any television at all was quite low at only $2.9 \%(\mathrm{~N}=3)$. Another response illustrated in Figure 6 shows $36.2 \%$ $(\mathrm{N}=38)$ of respondents stated that they also watched television (either live or recorded) "most evenings."

Finally, 26.7\% $(\mathrm{N}=28)$ of those surveyed said that while they did not watch a great deal of television, there were specific programs they made time to watch. This raises the additional question: Did they do so with or without the aid of a DVR?

\section{Conclusions}

The results should be interpreted as suggestive rather than conclusive. The purpose of the study was to generate evidence regarding the impact of DVR use on television viewing habits. Insights gained indicated that DVR users view a significant amount of advertising on a regular basis. The DVR has not heralded the end of the 30 -second

\section{Frequency at which DVR users stop fast-forwarding to view} advertisements

Figure 5:

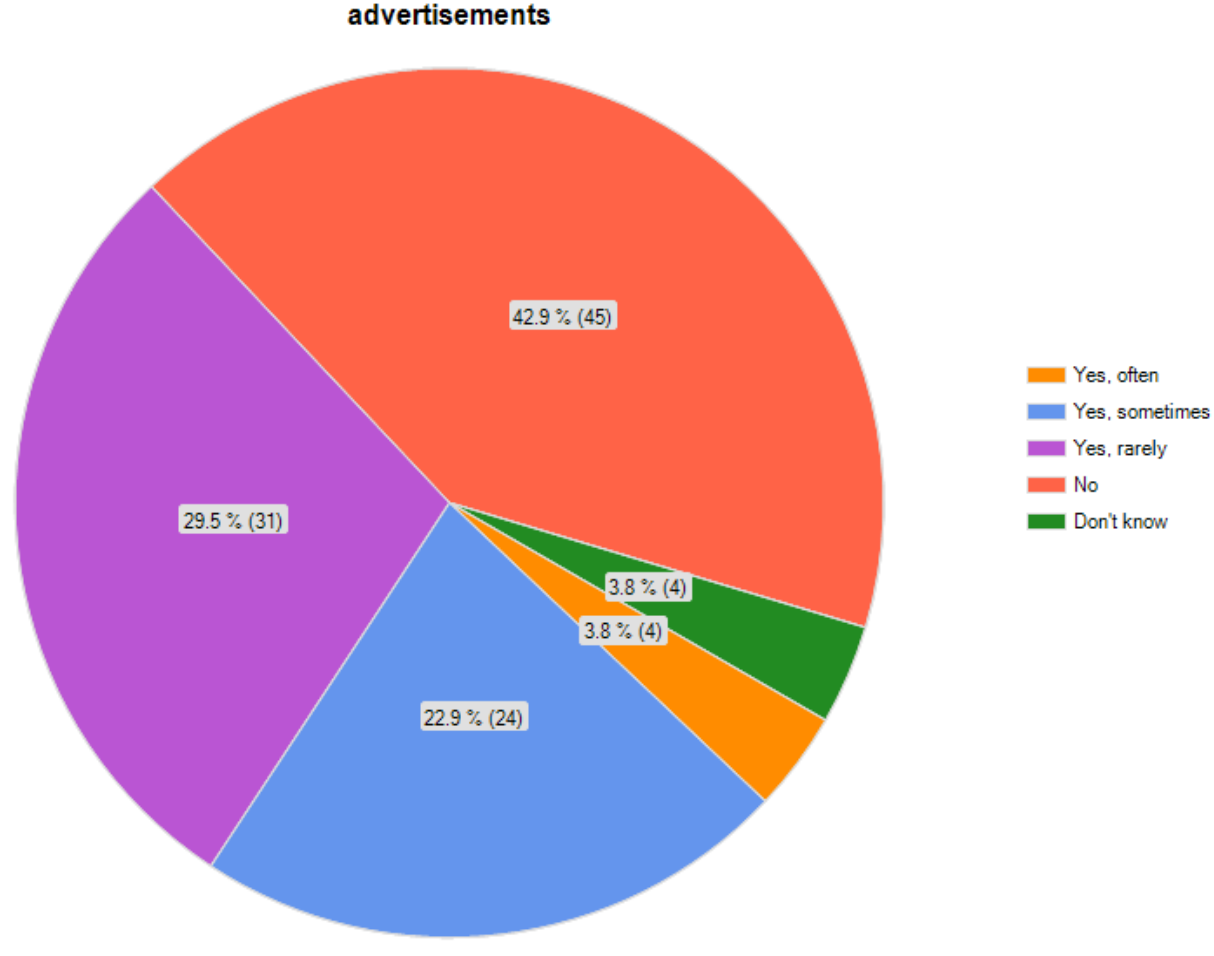




\section{How DVR users watch TV}

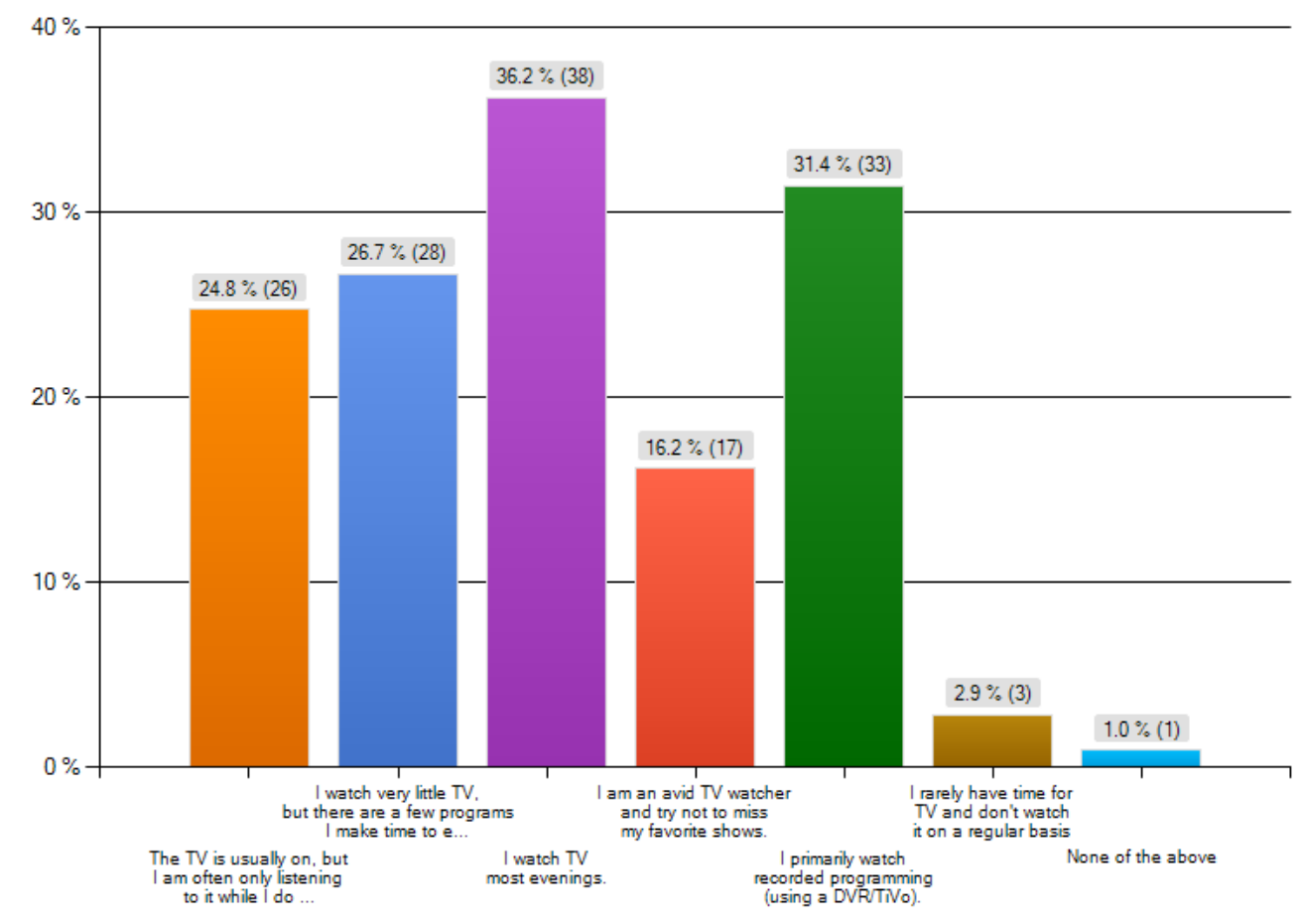

Figure 6:

commercial. Furthermore, $40.8 \%(\mathrm{~N}=42)$ reported that they watched more television as a direct result of having access to DVR technology. An additional $43.7 \%(\mathrm{~N}=45)$ of users said they could not be certain if they were watching more or less television overall.

Across the board, DVR users demonstrated positive recall of specific advertising messages, reporting in every instance that they actively stopped time-shifting in order to view ad content. The presence of DVRs does present advertisers with a new set of challenges. Greater than $85 \%(\mathrm{~N}=88)$ of DVR users responding across all demographics said that they sometimes forgot to fast-forward through advertising and found themselves watching commercials they did not intend to watch. This challenges the broad scale assumption that DVRs not only allow but encourage nonparticipation with advertising. Results generated indicate this reasoning may not be universally sound.

When questioned as to what the single most important feature or benefit of their DVR use was to them personally, $86.4 \%(\mathrm{~N}=89)$ of DVR users responding said that the device afforded them the convenience of recording programs and watching them later, contradicting the belief that ad skipping is the DVR user's first priority. Based on three distinct groups of respondents in a mid-southeastern college town, gender, age, and education had no measured impact on the use or non-use of a DVR, although use of such devices appeared to alter the ways in which television (and advertising) were viewed by the various market segments.

When DVR users were asked if they kept their eyes on the TV screen while fast-forwarding through advertising, 100\% ( $\mathrm{N}=105)$ of respondents answered in the affirmative. Clearly, this indicates greater possibilities for TV advertisers and the need to explore in-depth before negating the overall effectiveness of television advertising. Researchers have previously suggested that greater creativity is needed from the advertising industry to create broadcast advertising more people will watch. This study supports that conclusion.

Age, sex, and education levels as measured did not render sufficient data to determine whether or not advertising was skipped (via fastforwarding with a DVR) as a result of any demographic factors. Age, gender, and education may have little effect upon whether or not an individual owns or uses a DVR.

DVR use among a campus population paralleled the rate of use within the national population. Additional research is warranted to ascertain how much advertising viewers are responding to, seeing and perceiving. Continued study using eye-tracking and bio-metrics could benefit both the advertising and television industries. While the continued use of DVRs may, in fact, present a challenge to marketers and advertisers, new understanding of the ways in which viewers use DVR technology could help to maintain the integrity and effectiveness of television advertising.

\section{Limitation}

The researcher encountered difficulty with survey distribution. Like so many campuses which have been targeted by SPAM campaigns, excessive clutter in "edu" email accounts makes reaching today's campus population a challenge. To combat SPAM, Murray State University employs stringent filters on its email servers. This hindered the distribution of 1,025 email survey invitations which were quarantined for an indeterminate period within a SPAM filter. As a result, time was lost, and a smaller overall target audience was exposed to the survey instrument.

Additionally, 200 emails electronically "bounced" back to the 
Citation: Thomas EA (2012) DVR Pilot Study: Measuring Uses and Gratifications of Digital Video Recorders in Modern Television Viewing. J Mass Communicat Journalism 2:109. doi:10.4172/2165-7912.1000109

Page 9 of 9

researcher. These were ultimately deemed undeliverable. After correcting for the 200 unusable addresses, the response rate climbed to $29.5 \%$ (244 responses; 825 invitations).

In light of the initial low response, a secondary strategy was employed in which the survey invitation was additionally sent to 30 faculty members who were asked to forward a web link to their students. This allowed the addition of nine responses to reach the total of 244 respondents.

The study yielded valuable data regarding DVR usage and TV viewing habits, especially with regard to what types of programming was being viewed live versus recorded. While the research questions did not fully address all the findings, additional data generated may prove helpful to network programmers, advertisers or industry researchers as further statistical analysis is performed. Further study of the data is recommended. The online service provider, SurveyMonkey, limited the researcher's ability to analyze all data collected. Cross tabulation was the primary methodology used. SurveyMonkey's professional account, used strictly for purposes of the study, allowed cross-tabulation of a maximum of five variables at one time. Three of the research questions required analysis of six cross-tabbed variables, making the use if SurveyMonkey a limitation when analyzing for statistical relevance.

The study resulted in the generation of a wide range of information on issues related to DVR usage and modern television viewing. Further study is warranted, especially with regard to those portions of the survey instrument containing responses that indicated DVR ownership compelled the consumption of more television programming (and more advertising) while allowing viewers to save time and enjoy greater convenience.

\section{References}

1. Bernoff J (2004) Consumer Technographics Data Report. Trends, Forrester Research Inc.

2. Leichtman Research Group (2009) More Viewers Buy DVRs as appeared in USA Today.

3. OTX Data (2008) How Do You TiVo? MediaWee 18: 26-27.

4. von Rimscha M (2006) How the DVR is Changing the TV Industry-A SupplySide Perspective. JMM: The International Journal on Media Management 8: 116-124.

5. Levy M (1981) Home Video Recorders and Time Shifting. Journalism Quarterly 58: 401-405.

6. Ball-Rokeach SJ, DeFleur ML (1976) A Dependency Model of Mass-Media Effects. Communications Research 3: 3-21.

7. DuPlessisE(2009)DigitalVideoRecordersand InadvertentAdvertisingExposure. J Advert Resea 49: 236-239.

8. Fortunato JA, Windels DM (2005) Adoption of Digital Video Recorders and Advertising: Threats or Opportunities. J Intera Advert 6: 137-148.

9. Crupi A (2009) Study: Affluent Fond of Time-Shifting TV Devices. MediaWeek 19: 8.

10. IAG Research (2007) Most Engaging Shows Are Last Season's Holdovers. Television Week 26: 13.

11. http://www.ipsos.com/mediact/

12. Siefert C, Gallent J, Jacobs D, Levine B, Stipp H, et al (2008) Biometric and eye-tracking insights into the efficiency of information processing of television advertising during fast-forward viewing. Inter J Advert 27: 425-446.

13. Wilbur KC (2008) How the Digital Video Recorder (DVR) Changes Traditional Television Advertising. J Advert 37: 143-149.
14. Carlson M (2006) Tapping into TiVo: Digital video recorders and the transition from schedules to surveillance in television. New Media \& Society 8: 97-115.

15. Hamaker C (2009) Independents Usher in the Dawn of the DVR. Rural Telecommunications, 24: 46-51.

16. Downey K (2009) DVRs giving broadcast more gray hairs. Media Life Magazine-Research.

17. Anonymous report (2009) Digital Video Website Usage, and Mix of Revenue Models Expanding Rapidly. Ipsos MediaCT.

18. Baker W (2007) William F Baker on the state of American television. Daedalus 136: $141-144$

19. Bellman S, Varan D (2007) Digital Television as Persuasive Technology Springer Berlin/Heidelberg-publisher.

20. Callari R (2009) The Race for Clickable TV. Digital Media Buzz, blog.

21. Cistola J (2003) All this hand-wringing over DVRs misses a key point: They can be good for cable. Cable World, March 2003.

22. Fink AM (2007) Press Fast-Forward for TV Salvation. Advertising Age.

23. Hollis N (2008) Who's Afraid of the Big, Bad DVR? Marketing Insights webzine October 2008.

24. Johnson S (2009) DVRs offer a Gold Mine of Data for Advertisers. Television Week.

25. Kalter A (2003) Unnecessary Force. Adweek, June 30, 44: 18.

26. Karp S (2007) What Will Burst the TV Advertising Bubble? Publishing 2.0, June $27,2007$.

27. Masnick M (2007). Has the DVR Resulted in More Reality TV Programming? Techdirt blog, Changing-Times, April 30, 2007.

28. Neff J(2008) Study finds mixed DVR effects. Advertising Age, 79(12), March 24, 2008, 8. Retrieved on: September 5, 2009, from Business Source Premier Database.

29. Poniewozik J (2007) Is Your DVR Killing Advertising? Tuned In (a Time Magazine blog), posted October 8, 2009.

30. Shultz T (2009). DVR Research Institute Study: More Info Needed. TVWeek. com, January 21, 2009.

31. Siddarth S, Chattopadhyay A(1998) To Zap or Not to Zap: A Study of the Determinants of Channel Switching during Commercials. Marketing Science 17: 124-138. 